\title{
Tawny owl vocal activity is constrained by predation risk
}

\author{
Rui Lourenço, Fernando Goytre, Maria del Mar Delgado, Michael Thornton, João E. Rabaça \\ and Vincenzo Penteriani
}

R. Lourenço (ruifazendalourenco@gmail.com), M. del Mar Delgado and V. Penteriani, Dept of Conservation Biology, Doñana Biological Station, C.S.I.C., cl Americo Vespucio s/n, ES-41092 Seville, Spain. - RL and J. E. Rabaça, LabOr-Laboratory of Ornithology, Dept of Biology, Inst. de Ciências Agrárias e Ambientais Mediterrânicas, Univ. de Évora - Núcleo da Mitra, Ap. 94, PT-7002-554, Portugal. MdMD also at: Dept of Biosciences, FI-00014 Univ. of Helsinki, Finland. VP also at: Finnish Museum of Natural History, Zoological Museum, FI-00014 Univ. of Helsinki, Finland. - F. Goytre, Paseo Virgen del Puerto 41, $3^{\circ}$ A., ES-28005, Madrid, Spain. - M. Thornton, Scottish Natural Heritage, Silvan House, 231 Corstorphin Road, Edinburgh, EH12 7AT, Scotland.

\begin{abstract}
The vocal behaviour of birds may be influenced by many factors, including the risk of being detected by a predator. In Doñana Protected Area, the tawny owl co-exists alongside its intraguild predator, the eagle owl Bubo bubo. We considered four scenarios to study the vocal behaviour of tawny owls at dusk by analysing: A) the calling rate of all males in 29 sites; B) the calling rate at dusk of males living within the home range of the intraguild predator; C) the calling rate of males living within the home range of the intraguild predator between 60 and 90 min after sunset; and D) the duration of male vocal bouts in visits where eagle owls have called. In scenario A we found that only the number of conspecific males affected the calling rate of tawny owls. In scenario B we observed that the presence of an eagle owl calling constrained the calling rate of the intraguild prey. In scenario $\mathrm{C}$ we found that this effect seemed mostly associated to a contemporaneous detection of the intraguild predator's calls. Finally, in scenario D we found no significant effects on bout duration. These results seem to indicate that tawny owls use their intraguild predator's calls as a cue to assess predation risk, and then adjust their vocal behaviour in order to minimize predation risk by a predator that may locate its prey by its vocalizations.
\end{abstract}

Vocal communication serves many functions and is an important biological trait in birds (Gil and Gahr 2002). However, predation risk is among the most important factors that may influence the patterns of vocal activity in birds (Catchpole and Slater 1995), and changes induced by predation risk may affect its signalling functions, ultimately altering the fitness of individuals (Mougeot and Bretagnolle 2000a, b). Most owl species (Order Strigiformes) are top predators, which have nocturnal or crepuscular habits, and at the same time, rely greatly on vocal communication. Recent studies have shown that, despite their position on the top of food webs, owls may also be under predation risk by larger superpredators (Lourenço et al. 2011). However, our knowledge of how predation risk may alter the vocal activity of birds, and particularly owls, is still poor.

A number of factors are known to influence the patterns of vocal activity of nocturnal birds. One of the most obvious is the time of year, with calling rate varying within the breeding cycle (Palmer 1987, Smith et al. 1987, Ganey 1990, Morrell et al. 1991, Clark and Anderson 1997, Sunde and Bølstad 2004, Delgado and Penteriani 2007). Time of day also influences bird vocal activity, with most owl species being more vocally active during dusk and dawn (Ganey 1990, Clark and Anderson 1997, Penteriani et al. 2002, Delgado and Penteriani 2007, Hardouin et al. 2008). The breeding density of conspecifics is another well-known factor influencing vocal activity, namely in owls (Redpath 1995, Penteriani et al. 2002, Penteriani 2003, Sunde and Bølstad 2004). Calling is often stimulated by the calls of conspecifics (Ganey 1990), but the response intensity can be sex-specific and different towards neighbours and strangers (Galeotti and Pavan 1993, Appleby et al. 1999, Hardouin et al. 2006). Many studies have found that weather conditions can influence owl communication. For example, vocal activity is reduced in heavy rain and strong wind (Smith et al. 1987, Takats and Holroyd 1997, Lengagne and Slater 2002, Kissling et al. 2010), as well as by cold temperatures (Clark and Anderson 1997, Takats and Holroyd 1997, Hardouin et al. 2008). The effect of moon luminosity on owls has also been studied, reaching apparently contradictory results that owl species may either increase vocal displays during moonlit nights (Morrell et al. 1991, Clark and Anderson 1997, Takats and Holroyd 1997, Kissling et al. 2010), or call more in the last quarter and new moon phases of the lunar cycle (Ganey 1990). Recent studies have highlighted that owl 
communication also relies on visual cues (Penteriani et al. 2006, 2007, Galeotti and Rubolini 2007) and that the conspicuousness of their visual plumage traits is increased by the unusual light conditions during dusk (Penteriani and Delgado 2009) or during bright moonlight (Penteriani et al. 2010). Cloud cover also seems to have an effect on vocal activity. Great horned owls Bubo virginianus and spotted owls Strix occidentalis seem to call more with clear sky (Ganey 1990, Morrell et al. 1991), while other studies have shown no effects or contradictory results for other species (Palmer 1987, Clark and Anderson 1997, Swengel and Swengel 1997, Takats and Holroyd 1997).

In addition to all the above mentioned effects, because larger owl species can be predators or dominant competitors of smaller owls, predation risk and interference competition also have the potential to reduce vocal activity in smaller owls (Crozier et al. 2006, Zuberogoitia et al. 2008). A few studies found an increased calling rate in response to the calls of a larger owl, which has been explained by interspecific territoriality or mobbing behaviour (Ganey 1990, Boal and Bibles 2001, Crozier et al. 2005).

Our study focused on the predatory interaction (intraguild predation, a predator that eats a competitor sensu Polis et al. 1989) between two owl species, in a system where the intraguild prey (tawny owl Strix aluco) and its intraguild predator (eagle owl Bubo bubo) co-occur at higher densities in the same areas. This scenario presents an opportunity to examine the behavioural response of the intraguild prey when detecting the presence of its intraguild predator. The tawny owl is a resident and strongly territorial species, aggressively defending its home range from conspecifics (Southern and Lowe 1968, Hirons 1985, Redpath 1994, Sunde and Bølstad 2004). Tawny owls have distinctive vocalizations, and breeding adults discriminate the hooting of conspecific neighbours, showing a stronger reaction when faced with stranger males (Galeotti and Pavan 1991, 1993, Galeotti 1998). The eagle owl feeds primarily on small to medium sized mammals and birds, and it can frequently prey on both adult and young tawny owls (Lourenço et al. 2011). The conspicuous calls of adult and young tawny owls are probably an effective way used by eagle owls, a sit-and-wait predator, to detect this intraguild prey (Mougeot and Bretagnolle 2000a, Sergio et al. 2007, Penteriani et al. 2008). Intraguild predation risk can strongly influence habitat selection, density, breeding success and behaviour of the intraguild prey (Hakkarainen and Korpimäki 1996, Cresswell 2008, Sergio and Hiraldo 2008). Tawny owls have shown at least two different mechanisms to avoid superior competitors and predators: distance-mediate spatial avoidance; and habitat-mediated spatial avoidance (Korpimäki 1986, Vrezec and Tome 2004, Sergio et al. 2007). But, in situations where these mechanisms are not employed and intraguild predator and prey coexist in the same habitat, predation risk may affect tawny owl vocal behaviour. Our main hypothesis is that tawny owls reduce their vocal activity as a response to intraguild predation risk by eagle owls. We considered four scenarios to test this hypothesis. A) First, our most general expectation is that the vocal activity should be less intense in those tawny owl territories close to eagle owls. B) Second, we expect that the detection of a calling eagle owl should reduce the vocal activity of tawny owls with neighbouring eagle owls. C) Third, we expect that the negative effect of detecting an eagle owl calling should occur mostly on a contemporary time, i.e. tawny owls call less when have detected an eagle owl just a few minutes before. D) Fourth, we expect that tawny owl vocal displays should be shorter if preceded by an eagle owl calling, i.e. tawny owls call during shorter periods after detecting their potential intraguild predator in the vicinity.

\section{Methods}

\section{Study area}

The study was conducted in Doñana protected area, southwestern Spain $\left(37^{\circ} 0^{\prime} \mathrm{N}, 6^{\circ} 30^{\prime} \mathrm{W}\right)$, which covers 108429 ha and includes extensive wetlands in the estuary of the river Guadalquivir. Doñana National Park supports a great diversity of habitats including marshlands, scrublands and woodlands, and this study was undertaken in Mediterranean scrublands scattered with cork oaks Quercus suber; cork oak woodlands (with Pistacia lentiscus, Arbutus unedo, Myrtus communis); stone pine Pinus pinea and Eucalyptus plantations; and areas of mature riparian vegetation (Populus spp., Fraxinus angustifolia) alongside large cork oaks, stone pines, and eucalyptus.

\section{Data collection}

We defined 29 point count sites that covered most of our study area, and for which we had previous information of tawny owl presence, obtained during an owl census performed between September 2007 and February 2008 (275 sites). From March to April 2008, and September 2008 to March 2009, we completed 166 listening sessions, visiting each of the 29 sites between four and seven times. No listening sessions were carried out with rain or moderate/ strong wind. All listening sessions started $30 \mathrm{~min}$ before sunset and lasted for $2 \mathrm{~h}$. We recorded all vocalizations for all tawny owl and eagle owl individuals. Each listening session was divided in 120 one min time periods. We considered each tawny owl male detected in each visit to the 29 sites as an individual sample.

In the context of another research project in Doñana, we located and monitored 19 eagle owl breeding sites, from September 2007 to March 2009. This represented the total breeding population of this owl in Doñana during the period of this study (Penteriani et al. 2012).

\section{Data analysis}

As mentioned above, we considered four scenarios to test our hypothesis that the vocal behaviour of tawny owls is constrained by intraguild predation risk. A) In the first scenario, we considered the calling rate of all tawny owl males at dusk, i.e. the number of one-minute periods in which each tawny owl male performed any vocalization, and tested the effects of: 1) the density of conspecifics, i.e. the number of males detected in each listening session (interval variable); 2) living within the home range of the 
intraguild predator (binomial variable assessed by radiotracking eagle owls; Penteriani et al. 2012); and 3) the presence of an eagle owl calling at a distance closer than $800 \mathrm{~m}$ of the tawny owl male during the listening session (binomial variable). The $800 \mathrm{~m}$ distance was chosen based on our previous experience of the detectability of eagle owl calls by the observer, and, during this study, this limit included more than $97 \%$ of the locations from which eagle owls were detected calling. B) In the second scenario, we considered the calling rate at dusk of tawny owl males living within the home range of the intraguild predator, and tested the effects of: 1) the density of conspecifics; and 2) the presence of an eagle owl calling. C) In the third scenario, we considered the calling rate between 60 and 90 min after sunset of tawny owls living within the home range of the intraguild predator. This interval is when the calling rate was higher at dusk (Fig. 1), and the intraguild prey has greater probability of having obtained information on eagle owl presence by its vocalizations. We tested the effects of: 1) the density of conspecifics; 2) the presence of an eagle owl calling in the previous $30 \mathrm{~min}$ (30-60 $\mathrm{min}$ after sunset); and 3) the presence of an eagle owl calling in the same period (60-90 min after sunset). D) In the fourth scenario, we considered the duration of tawny owl vocal bouts (number of minutes) only in those visits where eagle owls have called. We defined a bout as a series of vocalizations that were not separated by more than $1 \mathrm{~min}$ from the next. When bouts were separated by less than $5 \mathrm{~min}$ we just considered the largest bout and if these had similar duration we always selected the first one. We tested the effects of: 1) the density of conspecifics; and 2) the presence of an eagle owl calling in the $5 \mathrm{~min}$ before the bout. We subtracted $1 \mathrm{~min}$ to the variables 'calling rate' in scenarios $\mathrm{A}$ and $\mathrm{B}$, and 'bout duration' in scenario $\mathrm{C}$ in order to avoid a zero-truncated distribution of the count data.

In all four scenarios, the variables calling rate and bout duration showed overdispersion, i.e. the variance was larger than the mean, therefore we used generalized linear mixed models (GLMM) with negative binomial distribution (log-link function) in all analyses. In the models for scenarios $\mathrm{A}, \mathrm{B}$ and $\mathrm{C}$ we used the 'NB2' parameterization (variance $=\mu(1+\mu / \mathrm{k})$ ), which is the usual formula for calculating variance in a negative binomial distribution, while in the model for scenario D we used the 'NB1' parameterization (variance $=\Phi \mu$ ), which is a parameterization that matches mean-variance relationship assumed by QuasiPoisson models. These options were taken by comparing the Akaike information criterion (AIC) of the alternative models using NB1 or NB2 parameterization. In order to deal with zero-inflation present in all samples, we also included a single constant term across the entire model, meaning that the level of zero-inflation is assumed as constant across the whole data set and cannot vary across groups or with covariates (Bolker et al. 2012a). In the models of scenarios $\mathrm{A}, \mathrm{B}$ and $\mathrm{C}$ we considered two crossed random effects: a) site; and b) season (1 - post-fledging dispersal and pair-bonding [September-November]; 2 - prelaying and courtship [December-January]; and 3 - incubation and fledging [February-April]; Cramp 1985, Zuberogoitia et al. 2004, Lourenço et al. unpubl.). Although it was our initial though, we could not include tawny owl male as a nested random effect within site because the models did not converge. Additionally, the decision of including tawny owl male as a random effect would always be based on the premise that individuals calling from an approximate direction and distance in subsequent visits where the same. In the model of scenario D we considered two nested random effects: a) site; and b) tawny owl male. The parameters were fitted by Laplace approximation (Bolker et al. 2008, Fournier et al. 2012). We did not perform model selection as we were interested in testing the possible effect of all explanatory variables. Model validation was based on the plots of residuals versus the fitted values. Finally, we performed an analysis across the four scenarios

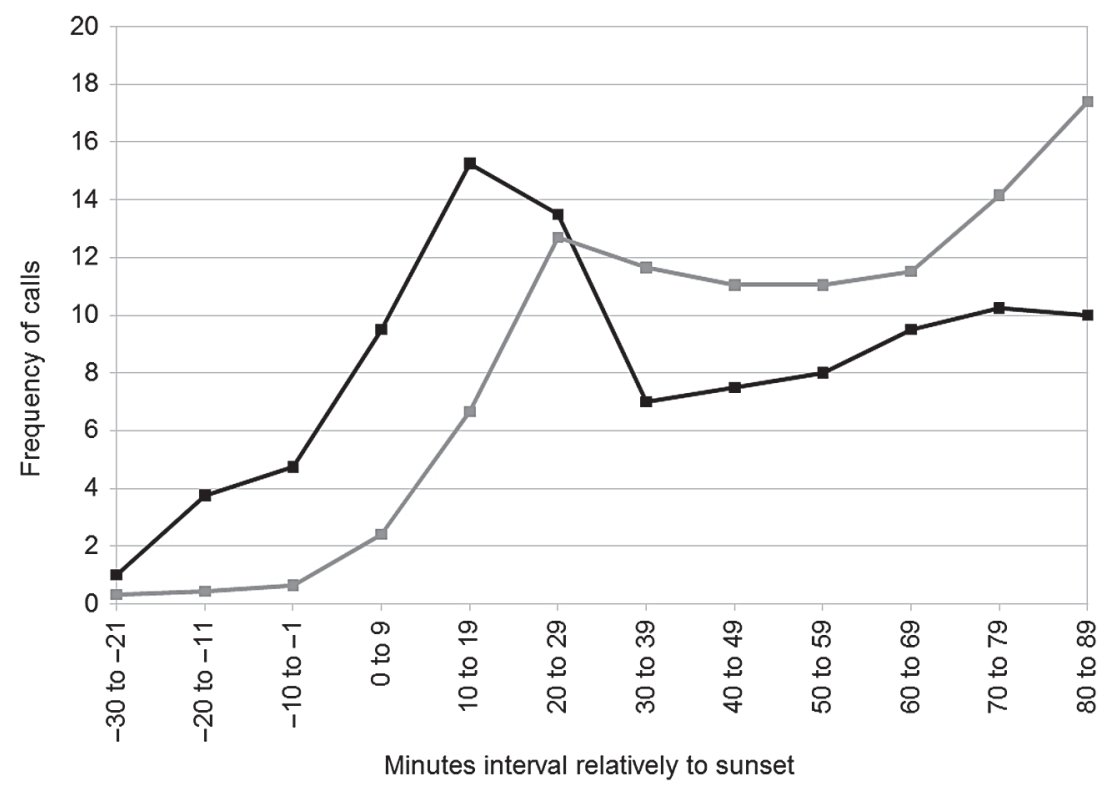

Figure 1. Frequency of calls of the eagle owl (black line) and the tawny owl (grey line) at dusk, i.e. the total number of vocalizations in each $10 \mathrm{~min}$ interval divided by the total number of vocalizations at dusk (120 min) of all tawny owl males in all listening sessions ( $\mathrm{n}=166)$. 
by combining the probabilities of the six independent tests of significance that analysed the potential effect of the eagle owl on the vocal activity of tawny owls. For this approach we used the Fisher's method which combines the p-values using the statistic S (Sokal and Rohlf 2011). Statistical significance was set to $p<0.05$. All statistical analysis were completed using software $\mathrm{R}$ ver. 2.15.0, with packages MASS (Venables and Ripley 2002), glmmADMB (Fournier et al. 2012, Skaug et al. 2012), and R2admb (Bolker et al. 2012b).

\section{Results}

We registered tawny owls calling in 116 sessions in all 29 sites, while eagle owls were registered in 36 sessions in 16 sites. The eagle owl and the tawny owl showed no significant differences in the frequency they called at dusk (from $30 \mathrm{~min}$ before sunset to $90 \mathrm{~min}$ after; two-sample KolmogorovSmirnov test: $\mathrm{D}=0.417, \mathrm{p}=0.25$ ), although the eagle owl seemed to call mostly in the first 30 min after sunset and the tawny owl between 60 and 90 min after sunset (Fig. 1).
In the model of scenario $\mathrm{A}$ we found that the calling rate of all tawny owl males at dusk $(\mathrm{n}=328$ in 29 sites, range $=0-55 \mathrm{~min}$ ) was positively influenced by the number of conspecific males calling (Fig. 2a), while no effect was found for living within the home range of the eagle owl, or for the presence of an eagle owl calling (Table 1).

In the model of scenario $B$ we found that the calling rate at dusk of only those tawny owl males living within the home range of the eagle owl $(n=228$ in 14 sites, range $=0-55$ $\mathrm{min}$ ) was positively influenced by the number of conspecific males and negatively influenced by the presence of an eagle owl calling (Table 1, Fig. 2b).

In the model of scenario $\mathrm{C}$ we found that the calling rate of tawny owls living within the home range of the eagle owl between 60 and $90 \mathrm{~min}$ after sunset $(\mathrm{n}=228$ in 14 sites, range $=0-30 \mathrm{~min}$ ) was positively influenced by the number of conspecific males and negatively influenced by the presence of an eagle owl calling in the same interval (Fig. 2c). The presence of an eagle owl calling in the previous interval had no significant effect (Table 1).

In the model of scenario $\mathrm{D}$ we found that the duration of tawny owl vocal bouts in the visits where eagle owls have
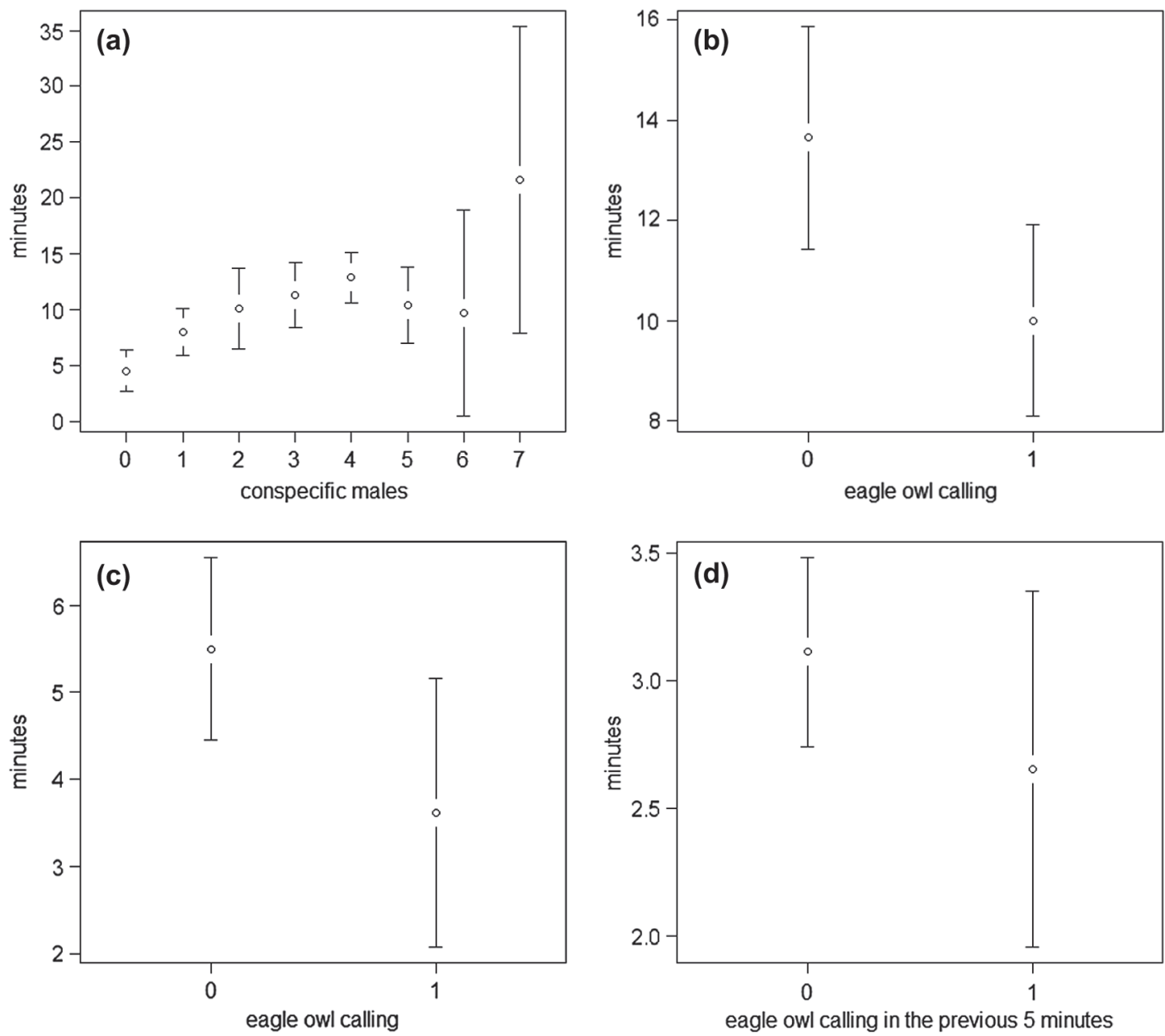

Figure 2. (a) Variation of the calling rate of tawny owls at dusk with the number of conspecific males (scenario A). (b) Variation of the calling rate of tawny owls at dusk with the presence of an eagle owl calling (scenario B). (c) Variation of the calling rate of tawny owls in the interval between 60-90 min after sunset with the presence of an eagle owl calling in the same interval (scenario C). (d) Variation of the bout duration of tawny owls with the presence of an eagle owl calling in the previous 5 min (scenario D). Plots of means and $95 \%$ confidence intervals. 
Table 1. Parameters of the zero-inflated negative binomial generalized linear models of scenarios A-D.

\begin{tabular}{|c|c|c|c|c|}
\hline Coefficient & $\beta$ & SE & z & p \\
\hline \multicolumn{5}{|c|}{ Scenario A $(n=328)$} \\
\hline Intercept & 1.680 & 0.201 & 8.37 & $<0.001$ \\
\hline Number of conspecific males & 0.159 & 0.045 & 3.51 & $<0.001$ \\
\hline Eagle owl home range $\left(0 \_1\right)$ & 0.124 & 0.211 & 0.59 & 0.56 \\
\hline Eagle owl calling $\left(0 \_1\right)$ & -0.179 & 0.151 & -1.19 & 0.23 \\
\hline Random effect & variance & SD & & \\
\hline Season $(n=3)$ & 0.012 & 0.107 & & \\
\hline Site $(n=29)$ & 0.104 & 0.323 & & \\
\hline Negative binomial dispersion parameter & $1.136(\mathrm{SE}=0.170)$ & & & \\
\hline Zero-inflation parameter & $0.065(\mathrm{SE}=0.029)$ & & & \\
\hline \multicolumn{5}{|c|}{ Scenario $B(n=228)$} \\
\hline Intercept & 2.235 & 0.197 & 11.32 & $<0.001$ \\
\hline Number of conspecific males & 0.105 & 0.048 & 2.17 & 0.030 \\
\hline Eagle owl calling $\left(0 \_1\right)$ & -0.365 & 0.158 & -2.30 & 0.021 \\
\hline Random effect & variance & SD & & \\
\hline Season $(n=2)$ & 0.003 & 0.050 & & \\
\hline Site $(n=14)$ & 0.025 & 0.159 & & \\
\hline Negative binomial dispersion parameter & $1.148(\mathrm{SE}=0.197)$ & & & \\
\hline Zero-inflation parameter & $0.060(\mathrm{SE}=0.031)$ & & & \\
\hline \multicolumn{5}{|c|}{ Scenario C $(n=228)$} \\
\hline Intercept & 1.092 & 0.271 & 4.03 & $<0.001$ \\
\hline Number of conspecific males & 0.211 & 0.059 & 3.58 & $<0.001$ \\
\hline Eagle owl calling 30-60 min (0_1) & 0.098 & 0.243 & 0.40 & 0.69 \\
\hline Eagle owl calling 60-90 min $\left(0 \_1\right)$ & -0.538 & 0.231 & -2.33 & 0.02 \\
\hline Random effect & variance & SD & & \\
\hline Season $(n=2)$ & 0.043 & 0.207 & & \\
\hline Site $(n=14)$ & 0.061 & 0.248 & & \\
\hline Negative binomial dispersion parameter & $1.024(\mathrm{SE}=0.240)$ & & & \\
\hline Zero-inflation parameter & $0.178(\mathrm{SE}=0.052)$ & & & \\
\hline \multicolumn{5}{|c|}{ Scenario $D(n=238)$} \\
\hline Intercept & 0.584 & 0.240 & 2.43 & 0.015 \\
\hline Number of conspecific males & 0.108 & 0.053 & 2.04 & 0.42 \\
\hline Eagle owl calling 5 min before $\left(0 \_1\right)$ & -0.383 & 0.220 & -1.74 & 0.082 \\
\hline Random effect & variance & SD & & \\
\hline Site $(n=14)$ & 0.018 & 0.133 & & \\
\hline Tawny owl male $(\mathrm{n}=83)$ within Site & $<0.001$ & $<0.001$ & & \\
\hline Negative binomial dispersion parameter & $2.785(\mathrm{SE}=0.515)$ & & & \\
\hline Zero-inflation parameter & $0.194(\mathrm{SE}=0.078)$ & & & \\
\hline
\end{tabular}

called ( $\mathrm{n}=238$ bouts, range $=0-12 \mathrm{~min}$ ) was positively influenced by the number of conspecifics, while the presence of an eagle owl calling in the $5 \mathrm{~min}$ before the bout had no significant effect (Table 1, Fig. 2d).

The combination of the probabilities of the six independent tests using the Fisher's method showed that, overall, the negative effect of the eagle owl on the vocal behaviour of tawny owls was significant $(p=0.013, S=25.39$, $\mathrm{DF}=12$ ).

\section{Discussion}

Despite the disadvantage of observational studies of usually having to deal with more factors influencing variability than experimental studies do, the former are able to closer reflect the reality of behaviours in natural conditions. In our study, although we had to deal with an amount of variance mostly related to variation in the density of conspecifics, we are able to say that our results indicate that the vocal behaviour of an intraguild prey, the tawny owl, is often constrained by the risk of intraguild predation by the eagle owl. Notwithstanding, intra-specific social pressures seem to be the main factor determining tawny owl vocal behaviour.

Doñana Protected Area is characterized by a high degree of habitat heterogeneity, and both owl species, like most diurnal raptors and mammalian carnivores, are mainly concentrated in highly productive areas, where prey abundance and breeding success are higher (Veiga and Hiraldo 1990, Viñuela et al. 1994, Ferrer and Donázar 1996, Casado et al. 2008). Consequently, those areas favoured by tawny owls also seem to be preferred by eagle owls. In agreement, we may say that in our study area, due to habitat heterogeneity, distance-sensitive and habitat-mediated predator avoidance may not be effective mechanisms which tawny owls can use to reduce predation risk by eagle owls (Sergio et al. 2007, Sergio and Hiraldo 2008). So, if tawny owls cannot avoid eagle owls because both species occupy the 
same patches of habitat, has the intraguild prey species developed any alternative behavioural mechanism to reduce predation risk?

Tawny owls did not seem to give up calling completely as a result of having an eagle owl nearby, however they did reduce how much they called, and this may be interpreted as a behavioural mechanism to avoid being located by their intraguild predator and thereby reducing predation risk (anti-predator mechanism; Hileman and Brodie 1994). We considered two kinds of cues that tawny owls may use to assess intraguild predation risk. The first is the variable used to analyse the effect of living within the home range of an eagle owl. In this case, the level of perceived predation risk should be constant along time. We found no significant effect of this variable on the calling rate of tawny owls, which may either indicate that: 1) tawny owls do not have a clear perception of the home range of their intraguild predator; or that 2) despite the perception of living close to their intraguild predator, tawny owls did not reduce their vocal activity based on this cue. The second kind of cue is detecting an eagle owl calling, which represents an immediate cue of predation risk, varying on a moment-to-moment basis (Lima and Dill 1990). When an eagle owl calls, a tawny owl can gauge its predator's location, and thereby temporarily assess the level of predation risk, and adjust its behaviour in agreement to this (Brown et al. 1999, Lima and Bednekoff 1999). Our results indicate that the presence of an eagle owl vocalizing was related to a lower calling rate of tawny owls at dusk, which supports the hypothesis that tawny owls can use their predator's calls as a cue of predation risk and accordingly adapt their calling rate to reduce the risk of being detected by a top predator (Zuberogoitia et al. 2008). Eagle owls have a calling peak around sunset (Delgado and Penteriani 2007), and the same pattern of vocalization was observed in our study area. As tawny owls generally start calling after sunset (Fig. 1), they should have time to collect information about the presence of an eagle owl in the proximity, evaluate the predation risk and, in agreement with the predation risk allocation hypothesis (Lima and Bednekoff 1999), adjust the intensity of their vocal activity. We also found that the calling rate of tawny owls seemed mostly influenced by the presence of an eagle owl calling in a contemporaneous period, which indicates that this cue may result in a different response by tawny owls depending on the lag since they obtained it. The results about the duration of the vocal bouts were not conclusive, but since the presence of an eagle owl calling 5 min earlier was close to significance, it would be important to do further tests.

However, the use of the intraguild predator's calls as a defence mechanism may not be totally reliable, due to the fact that tawny owls obtain imperfect information, as an eagle owl may still be nearby without announcing its presence by calling (Brown et al. 1999). Thus, in order to coexist with eagle owls, tawny owls may need additional cues (not tested here) that enable them to employ effective predator-avoidance and anti-predator mechanisms. Still, for tawny owls, reducing the calling rate might contribute to decrease encounter rate and time spent vulnerable to attack (Lima and Dill 1990).

Vocalizations play a fundamental role in territorial defence, sexual selection and intra-pair communication in most birds, including owls (Penteriani 2002, 2003, Sunde and Bølstad 2004), and tawny owls are known to defend their territories very aggressively (Hirons 1985, Sunde and Bølstad 2004). In our study, the number of conspecific males had major influence in the calling rate of tawny owls at dusk. Therefore, in situations of high density of tawny owl males occurring alongside eagle owls, the priority of territorial defence may outweigh the need to reduce vocal behaviour to diminish predation risk, even considering the potential lethal costs of predation. Tawny owls may have established a trade-off between the conflicting pressures of territorial functions of vocalizations and the need to reduce predation risk, based on a moment-to-moment cue, which is the ability to detect an eagle owl calling in the proximity. In this situation predation risk may represent a cost of reproduction (Magnhagen 1991), however the investment put into vocal advertising should result from the complex interaction between habitat quality, individual quality and conspecific density.

In conclusion, a number of behavioural mechanisms have been identified in tawny owls which may reduce predation risk (Vrezec and Tome 2004, Sergio et al. 2007; this study) however, is there a cost dependent hierarchy in behaviours which tawny owls employ to reduce predation risk? It is possible that an intraguild prey species first employs antipredator mechanisms (e.g. reducing its calling rate) to survive encounters, resulting in a minimal cost to fitness. If these behavioural mechanisms do not effectively minimize predation risk (e.g. a predator which is too efficient), a range of more costly predator-avoidance mechanisms may be employed, such as avoiding habitats associated with a high predation risk or even avoiding proximity to predators independent of habitats (Hileman and Brodie 1994, Hakkarainen et al. 2001). Besides vocal activity, possibly also other behavioural traits of tawny owls may be affected by eagle owls and other top predators. Changes in traits such as foraging behaviour and microhabitat use may potentially influence population dynamics of tawny owls, as well as the relationships between tawny owls and their prey, as a cascading effect of intraguild predation risk. However, it remains much to unravel about the mechanisms by which super-predators can impact mesopredators.

Acknowledgements - We would like to thank L. Campioni and G. Szabó for their help with fieldwork; and P. Sunde, E. Korpimäki and S. Santos for comments on the manuscript. This study was funded by a research project of the Consejería de Medio Ambiente Junta de Andalucía, Spain (EXPTE.:700/2005/M/00./). RL was supported by a doctoral degree grant $(\mathrm{BD} / 27434 / 2006)$ and a post-doctoral degree grant (BPD/78241/2011) from Fundação para a Ciência e Tecnologia, Portugal. VP was grant funded by the Spanish Secretaría General de Universidades, Ministry of Education (Salvador de Madariaga Program).

\section{References}

Appleby, B. M., Yamaguchi, N., Johnson, P. J. and MacDonald, D. W. 1999. Sex-specific territorial responses in tawny owls Strix aluco. - Ibis 141: 91-99.

Boal, C. W. and Bibles, B. D. 2001. Responsiveness of elf owls to conspecific and great horned owl calls. - J. Field Ornithol. 72: 66-71. 
Bolker, B. M., Brooks, M. E., Clark, C. J., Geange, S. W., Poulsen, J. R., Stevens, M. H. H. and White, J.-S. S. 2008. Generalized linear mixed models: a practical guide for ecology and evolution. - Trends Ecol. Evol. 24: 127-135.

Bolker, B., Skaug, H., Magnusson, A. and Nielsen, A. 2012a. Getting started with the glmmADMB package. $-<$ http:// glmmadmb.r-forge.r-project.org/glmmADMB.pdf $>$

Bolker, B., Skaug, H. and Laake, J. 2012b. R2admb: ADMB to $\mathrm{R}$ interface functions. $\mathrm{R}$ package ver. 0.7.5.3. - < https:// $\mathrm{r}$-forge.r-project.org/projects/r2admb/>

Brown, J. S., Laundré, J. W. and Gurung, M. 1999. The ecology of fear: optimal foraging, game theory and trophic interactions. - J. Mammal. 80: 385-399.

Casado, E., Suárez-Seoane, S., Lamelin, J. and Ferrer, M. 2008. The regulation of brood reduction in booted eagles Hieraaetus pennatus through habitat heterogeneity. - Ibis 150: 788-798.

Catchpole, C. K. and Slater, P. J. B. 1995. Bird song: biological themes and variations. - Cambridge Univ. Press.

Clark, K. A. and Anderson, S. H. 1997. Temporal, climatic and lunar factors affecting owl vocalizations of western Wyoming. - J. Raptor Res. 31: 358-363.

Cramp, S. (ed.) 1985. Birds of western Palearctic. Vol. IV. - Oxford Univ. Press.

Cresswell, W. 2008. Non-lethal effects of predation in birds. - Ibis 150: 3-17.

Crozier, M. L., Seamans, M. E. and Gutiérrez, R. J. 2005. The effect of broadcasting great horned owl vocalizations on spotted owl vocal responsiveness. - J. Raptor Res. 39: $111-118$

Crozier, M. L., Seamans, M. E., Gutiérrez, R. J., Loschl, P. J., Horn, R. B., Sovern, S. G. and Forsman, E. D. 2006. Does the presence of barred owls suppress the calling behavior of spotted owls? - Condor 108: 760-769.

Delgado, M. M. and Penteriani, V. 2007. Vocal behaviour and neighbour spatial arrangement during vocal displays in eagle owls (Bubo bubo). - J. Zool. 271: 3-10.

Ferrer, M. and Donázar, J. A. 1996. Density-dependent fecundity by habitat heterogeneity in an increasing population of Spanish imperial eagles. - Ecology 77: 69-74.

Fournier, D. A., Skaug, H. J., Ancheta, J., Ianelli J., Magnusson A., Maunder, M. N., Nielsen, A. and Sibert, J. 2012. AD Model Builder: using automatic differentiation for statistical inference of highly parameterized complex nonlinear models. - Optim. Methods Softw. 27: 233-249.

Galeotti, P. 1998. Correlates of hoot rate and structure in male tawny owls Strix aluco: implications for male rivalry and female mate choice. - J. Avian Biol. 29: 25-32.

Galeotti, P. and Pavan, G. 1991. Individual recognition of male tawny owls (Strix aluco) using spectrograms of their territorial calls. - Ethol. Ecol. Evol. 3: 113-126.

Galeotti, P. and Pavan, G. 1993. Differential responses of territorial tawny owls Strix aluco to the hooting of neighbours and strangers. - Ibis 135: 300-304.

Galeotti, P. and Rubolini, D. 2007. Head ornaments in owls: what are their functions. - J. Avian Biol. 38: 731-736.

Ganey, J. L. 1990. Calling behavior of spotted owls in northern Arizona. - Condor 92: 485-490.

Gil, D. and Gahr, M. 2002. The honesty of bird song: multiple constraints for multiple traits. - Trends Ecol. Evol. 17: $133-141$.

Hakkarainen, H. and Korpimäki, E. 1996. Competitive and predatory interactions among raptors: an observational and experimental study. - Ecology 77: 1134-1142.

Hakkarainen, H., Ilmonen, P., Koivunen, V. and Korpimäki, E. 2001. Experimental increase of predation risk induces breeding dispersal of Tengmalm's owl. - Oecologia 126: 355-359.
Hardouin, L. A., Tabel, P. and Bretagnolle, V. 2006. Neighbourstranger discrimination in the little owl, Athene noctua. - Anim. Behav. 72: 105-112.

Hardouin, L. A., Robert, D. and Bretagnolle, V. 2008. A dusk chorus effect in a nocturnal bird: support for mate and rival assessment functions. - Behav. Ecol. Sociobiol. 62: 1909-1918.

Hileman, K. S. and Brodie, E. D. 1994. Survival strategies of the salamander Desmognathus ochrophaeus: interaction of predator avoidance and anti-predator mechanisms. - Anim. Behav. 47: 1-6.

Hirons, G. J. M. 1985. The effects of territorial behaviour on the stability and dispersion of tawny owl (Strix aluco) populations. - J. Zool. 1: 21-48.

Korpimäki, E. 1986. Niche relationships and life-history tactics of three sympatric Strix owl species in Finland. - Ornis Scand. 17: 126-132.

Kissling, M. L., Lewis, S. B. and Pendleton, G. 2010. Factors influencing the detectability of forest owls in southeastern Alaska. - Condor 112: 539-548.

Lengagne, T. and Slater, P. J. B. 2002. The effects of rain on acoustic communication: tawny owls have good reason for calling less in wet weather. - Proc. R. Soc. B 269: 2121-2125.

Lima, S. L. and Dill, L. M. 1990. Behavioral decisions made under the risk of predation: a review and prospectus. - Can. J. Zool. 68: 619-640.

Lima, S. L. and Bednekoff, P. A. 1999. Temporal variation in danger drives antipredator behavior: the predation risk allocation hypothesis. - Am. Nat. 153: 649-659.

Lourenço, R., Santos, S., Rabaça, J. E. and Penteriani, V. 2011. Superpredation patterns in four large European raptors. - Popul. Ecol. 53: 175-185.

Magnhagen, C. 1991. Predation risk as a cost of reproduction. - Trends Ecol. Evol. 6: 183-186.

Morrell, T. E., Yahner, R. H. and Harkness, W. L. 1991. Factors affecting detection of great horned owls by using broadcast vocalizations. - Wildl. Soc. Bull. 19: 481-488.

Mougeot, F. and Bretagnolle, V. 2000a. Predation as a cost of sexual communication in nocturnal seabirds: an experimental approach using acoustic signals. - Anim. Behav. 60: 647-656.

Mougeot, F. and Bretagnolle, V. 2000b. Predation risk and moonlight avoidance in nocturnal seabirds. - J. Avian Biol. 31: 376-386.

Palmer, D. A. 1987. Annual, seasonal, and nightly variation in calling of boreal and northern saw-whet owls. - In: Nero, R. W., Clark, R. J., Knapton, R. J. and Hamre, R. H. (eds), Biology and conservation of northern forest owls. USDA Forest Service, Gen. Tech. Rep. RM-142, pp. 162-168.

Penteriani, V. 2002. Variation in the function of eagle owl vocal behaviour: territorial defence and intra-pair communication. - Ethol. Ecol. Evol. 14: 275-281.

Penteriani, V. 2003. Breeding density affects the honesty of bird vocal displays as possible indicators of male/territory quality. - Ibis 145: E127-E135.

Penteriani, V. and Delgado, M. M. 2009. The dusk chorus from an owls perspective: eagle owls vocalize when their whit throat bradge constrasts most. - PLoS One 4: e4960.

Penteriani, V., Gallardo, M. and Cazassus, H. 2002. Conspecific density biases passive auditory surveys. - J. Field Ornithol. 73: 387-391.

Penteriani, V., Alonso-Alvarez, C., Delgado, M. M. and Sergio, F. 2006. Brightness variability in the white badge of the eagle owl. - J. Avian Biol. 37: 110-116.

Penteriani, V., Delgado, M. M., Alonso-Alvarez, C. and Sergio, F. 2007. The importance of visual cues for nocturnal species: eagle owls signal by badge brightness. - Behav. Ecol. 18: 143-147. 
Penteriani, V., Delgado, M. M., Bartolommei, P., Maggio, C., Alonso-Alvarez, C. and Holloway, G. J. 2008. Owls and rabbits: predation against substandard individuals of an easy prey. - J. Avian Biol. 39: 215-221.

Penteriani, V., Delgado, M. M., Campioni, L. and Lourenço, R. 2010. Moonlight makes owls more chatty. - PLoS One 5: e8696.

Penteriani, V., Lourenço, R. and Delgado, M. M. 2012. Eagle owls in Doñana: a conservation dilemma or not? - Brit. Birds 105: 88-95.

Polis, G. A., Myers, C. A. and Holt, R. D. 1989. The ecology and evolution of intraguild predation: potential competitors that eat each other. - Annu. Rev. Ecol. Syst. 20: 297-330.

Redpath, S. M. 1994. Censusing tawny owls Strix aluco by the use of imitation calls. - Bird Study 41: 192-198.

Redpath, S. M. 1995. Habitat fragmentation and the individual: tawny owls Strix aluco in woodland patches. - J. Anim. Ecol. 64: 652-661.

Sergio, F. and Hiraldo, F. 2008. Intraguild predation in raptor assemblages: a review. - Ibis 150 (Suppl. 1): 132-145.

Sergio, F., Marchesi, L., Pedrini, P. and Penteriani, V. 2007. Coexistence of a generalist owl with its intraguild predator: distance-sensitive or habitat-mediated avoidance? - Anim. Behav. 74: 1607-1616.

Skaug, H., Fournier, D., Nielsen, A., Magnusson, A. and Bolker, B. 2012. glmmADMB: generalized linear mixed models using $\mathrm{AD}$ model builder. $\mathrm{R}$ package ver. 0.7.3. $-<$ http:// R-Forge. R-project.org/projects/glmmadmb/>

Smith, D. G., Devine, A. and Walsh, D. 1987. Censusing screech owls in southern Connecticut. - In: Nero, R. W., Clark, R. J., Knapton, R. J. and Hamre, R. H. (eds), Biology and conservation of northern forest owls. USDA Forest Service, Gen. Tech. Rep. RM-142, pp. 255-267.

Sokal, R. R. and Rohlf, F. J. 2011. Biometry: the principles and practice of statistics in biological research, 4th ed. - W. H. Freeman and Co.
Southern, H. N. and Lowe, V. P. W. 1968. The pattern of distribution of prey and predation in tawny owl territories. - J. Anim. Ecol. 37: 75-97.

Sunde, P. and Bølstad, M. S. 2004. A telemetry study of the social organization of a tawny owl (Strix aluco) population. - J. Zool. 263: 65-76.

Swengel, A. B. and Swengel, S. R. 1997. Auditory surveys for northern saw-whet owls (Aegolius acadicus) in southern Wisconsin 1986-1996. - In: Nero, R. W., Clark, R. J., Knapton, R. J. and Hamre, R. H. (eds), Biology and conservation of northern forest owls. USDA Forest Service, Gen. Tech. Rep. RM-142, pp. 411-420.

Takats, D. L. and Holroyd, G. L. 1997. Owl broadcast surveys in the Foothills Model forest, Alberta, Canada. - In: Nero, R. W., Clark, R. J., Knapton, R. J. and Hamre, R. H. (eds), Biology and conservation of northern forest owls. USDA Forest Service, Gen. Tech. Rep. RM-142, pp. 421-431.

Veiga, J. P. and Hiraldo, F. 1990. Food habits and the survival and growth of nestlings in two sympatric kites (Milvus milvus and Milvus migrans). - Holarct. Ecol. 13: 62-71.

Venables, W. N. and Ripley, B. D. 2002. Modern applied statistics with $S$, 4th ed. - Springer.

Vińuela, J., Villafuerte, R. and De Le Court, C. 1994. Nesting dispersion of a black kite population in relation to location of rabbit warrens. - Can. J. Zool. 72: 1680-1683.

Vrezec, A. and Tome, D. 2004. Altitudinal segregation between Ural owl Strix uralensis and tawny owl $S$. aluco: evidence for competitive exclusion in raptorial birds. - Bird Study 51: 264-269.

Zuberogoitia, I., Martínez, J. A., Iraeta, A., Azkona, A. and Castillo, I. 2004. Possible first record of double brooding in the tawny owl Strix aluco. - Ardeola 51: 437-439.

Zuberogoitia, I., Martínez, J. E., Zabala, J., Martínez, J. A., Azkona, A., Castillo, I. and Hidalgo, S. 2008. Social interactions between two owl species sometimes associated with intraguild predation. - Ardea 96: 109-113. 